Check for updates

Cite this: Mater. Adv., 2020, 1,363

Received 9th April 2020, Accepted 3rd May 2020

DOI: 10.1039/d0ma00187b

rsc.li/materials-advances

\title{
High-efficiency and stable photocatalytic hydrogen evolution of rhenium sulfide co-catalyst on $\mathrm{Zn}_{0.3} \mathrm{Cd}_{0.7} \mathrm{~S} \dagger$
}

\author{
Jindi Huang, ${ }^{a}$ Xin Li, ${ }^{a}$ Xiaoli Jin, ${ }^{a}$ Li Wang, ${ }^{a}$ Yu Deng, ${ }^{b}$ Fengyun Su, ${ }^{a}$ \\ Po Keung Wong (iD ${ }^{c}$ and Liqun Ye (D) *ab
}

\begin{abstract}
Photocatalytic hydrogen evolution is an attractive technology to solve the growing energy crisis. The development of advanced photocatalysts is an attractive but challenging issue. For the first time, we use inorganic $\mathrm{ReS}_{2}$ as a co-catalyst for $\mathrm{Zn}_{0.3} \mathrm{Cd}_{0.7} \mathrm{~S}$ using a solvent thermal method, which enables highly efficient and recyclable $\mathrm{H}_{2}$ evolution. The $\mathrm{Zn}_{0.3} \mathrm{Cd}_{0.7} \mathrm{~S} / \mathrm{ReS}_{2}$ composite photocatalysts contain 4 wt\% $\mathrm{ReS}_{2}$ co-catalysts, and $\mathrm{Na}_{2} \mathrm{~S}-\mathrm{Na}_{2} \mathrm{SO}_{3}$ is used as the sacrificial reagent. Compared with bare $\mathrm{Zn}_{0.3} \mathrm{Cd}_{0.7} \mathrm{~S}$, $\mathrm{Zn}_{0.3} \mathrm{Cd}_{0.7} \mathrm{~S} / \mathrm{ReS}_{2}$ corresponds to 101 fold enhancement with the highest photocatalytic $\mathrm{H}_{2}$ evolution rates of $92.45 \mathrm{mmol} \mathrm{h}^{-1} \mathrm{~g}^{-1}$. Furthermore, it still maintains high hydrogen production after a 30 hours cycle experiment. In this paper, the mechanism of photocatalytic enhancement is expounded by various experimental methods. In situ Fourier Transform Infrared (FT-IR) spectra and online mass spectrometry were used to discover the sources of hydrogen. The experimental results show that $\mathrm{ReS}_{2}$ is a promising joint catalyst for obtaining high-gloss catalytic hydrogen from water under visible light.
\end{abstract}

\section{Introduction}

Hydrogen is considered to be a clean energy source, which could solve problems in the future such as the scarcity of fossil resources. However, the use of renewable resources rather than fossil fuels to produce hydrogen is a fundamental technical challenge. ${ }^{1,2}$ Honda and Fujishima presented the concept of photoelectrochemical decomposition of water into $\mathrm{H}_{2}$ and $\mathrm{O}_{2}$, which converts solar energy into chemical energy and/or electrical energy. ${ }^{3,4}$ In recent years, using photocatalytic reactions of semiconductors to generate hydrogen from water has attracted considerable interest, and many semiconductor photocatalysts have been discovered including sulfides, nitrides, metals/metal oxides, and so on. ${ }^{5-8}$ Among them, metal sulfides and their composites are regarded as good candidates for photocatalytic $\mathrm{H}_{2}$ production because of their suitable band gap and catalytic functions. CdS is the most widely used metal sulfide photocatalytic material for

\footnotetext{
${ }^{a}$ Engineering Technology Research Center of Henan Province for Solar Catalysis, College of Chemistry and Pharmaceutical Engineering, Nanyang Normal University, Nanyang 473061, P. R. China. E-mail: yeliquny@163.com

${ }^{b}$ College of Materials and Chemical Engineering, Key Laboratory of Inorganic Nonmetallic Crystalline and Energy Conversion Materials, China Three Gorges University, Yichang 443002, P. R. China. E-mail: lqye@ctgu.edu.cn

${ }^{c}$ School of Life Sciences, The Chinese University of Hong Kong, Shatin, NT, Hong Kong SAR, P. R. China

$\dagger$ Electronic supplementary information (ESI) available. See DOI: 10.1039/ d0ma00187b
}

photocatalytic hydrogen production. It has a band gap of $2.4 \mathrm{eV}$, absorbs visible light, and has a suitable redox potential. However, CdS particles are easily agglomerated into irregular large-sized particles, resulting in the reduction of specific surface area, with a high degree of recombination of photogenerated electrons and holes, and being prone to photocorrosion, which severely limits the photocatalytic efficiency. To solve the above problems, a variety of effective methods, such as element doping, construction of heterogeneous knots, or the use of co-catalysts, has been developed. ${ }^{9-11}$

Compared with CdS, ZnS has a better performance, but the band gap of $\mathrm{ZnS}$ is $3.6 \mathrm{eV}$, which allows it to absorb only the energy of ultraviolet light. In order to take full advantage of their respective advantages, $\mathrm{CdS}$ and $\mathrm{ZnS}$ are combined to form a $\mathrm{Zn}_{x} \mathrm{Cd}_{1-x} \mathrm{~S}$ solid solution as a high-efficiency catalyst for light. ${ }^{12}$ For example, Xing et al. synthesized a $\mathrm{Zn}_{x} \mathrm{Cd}_{1-x} \mathrm{~S}$ solid solution using a simple coprecipitation method and $\mathrm{N}_{2}$ atmosphere heat treatment. ${ }^{13}$ By adjusting the ratio of $\mathrm{Zn}$ to $\mathrm{Cd}$, the forbidden bandwidth of the $\mathrm{Zn}_{x} \mathrm{Cd}_{1-x} \mathrm{~S}$ solid solution is between $2.20 \mathrm{eV}$ and $3.12 \mathrm{eV}$. Although the $\mathrm{Zn}_{x} \mathrm{Cd}_{1-x} \mathrm{~S}$ solid solution exhibits higher photocatalytic activity than the onecomponent $\mathrm{ZnS}$ and $\mathrm{CdS},{ }^{14-17}$ these solid solutions still exhibit lower photocatalytic efficiency. Therefore, finding new solutions is necessary.

2D transition metal trihalides (TMDs), such as $\mathrm{MoS}_{2}$ and $\mathrm{WS}_{2}$, have large interlayer spaces and weak interlayer interactions, and have been widely studied as effective catalysts for 
hydrogen evolution. ${ }^{18,19}$ Recently, it is confirmed that a new type of TMD, rhenium disulfide $\left(\mathrm{ReS}_{2}\right)$, has extraordinary photocatalytic properties due to its remarkable electron-hole separation and is a promising photocatalyst for hydrogen production. ${ }^{20-24}$ With this in mind, we expect $\operatorname{ReS}_{2}$ to act as a cocatalyst to further enhance the photocatalytic performance, which may provide new opportunities for photocatalytic $\mathrm{H}_{2}$ evolution. ${ }^{25-31}$ However, to the best of our knowledge, it has rarely been reported as a cocatalyst for photocatalytic hydrogen production.

In this work, $\mathrm{ReS}_{2}$ was successfully loaded onto $\mathrm{Zn}_{x} \mathrm{Cd}_{1-x} \mathrm{~S}$ nanorods using a simple two-step hydrothermal method. The $\mathrm{Zn}_{x} \mathrm{Cd}_{1-x} \mathrm{~S}$ nanorods provide a substrate for the loading of $\mathrm{ReS}_{2}$. The introduction of $\mathrm{ReS}_{2}$ enables the transfer of photogenerated electrons, inhibits carrier recombination and improves the stability of $\mathrm{Zn}_{x} \mathrm{Cd}_{1-x} \mathrm{~S}$ during a photocatalytic reaction. Therefore, $\mathrm{Zn}_{x} \mathrm{Cd}_{1-x} \mathrm{~S}$ with $\mathrm{ReS}_{2}$ as a cocatalyst exhibits higher hydrogen production performance and stability. The optimum performance is confirmed by adjusting the ratio of zinc/Cd and the amount of $\mathrm{ReS}_{2}$ loaded. These results reveal that the $\mathrm{ReS}_{2} /$ $\mathrm{Zn}_{0.3} \mathrm{Cd}_{0.7} \mathrm{~S}$ composite loaded with $4 \mathrm{wt} \% \mathrm{ReS}_{2}$ exhibits the highest hydrogen production rate of $92.45 \mathrm{mmol} \mathrm{h}^{-1} \mathrm{~g}^{-1}$, and it has a stable hydrogen production rate for more than 30 hours when $\mathrm{Na}_{2} \mathrm{~S}-\mathrm{Na}_{2} \mathrm{SO}_{3}$ is used as the sacrificial reagent.

\section{Experimental section}

\subsection{Materials preparation}

Synthesis of $\mathbf{Z n}_{\boldsymbol{x}} \mathbf{C d} \mathbf{d}_{1-\boldsymbol{x}} \mathbf{S}$ nanorods. In a typical synthesis of $\mathrm{Zn}_{x} \mathrm{Cd}_{1-x} \mathrm{~S}$ nanorods $(x=0,0.1,0.2,0.3,0.4,0.5,0.7$ and 1$)$, $2 \mathrm{mmol}$ L-cysteine, zinc acetate and dihydrate cadmium acetate amounting to a total concentration of $1 \mathrm{mmol}$ with various molar ratios were dissolved in $35 \mathrm{~mL}$ of a binary solution of ethanol amine. The reaction suspension was stirred vigorously for $0.5 \mathrm{~h}$ until a homogeneous dispersion was formed. Then, the solution was transferred into a Teflon-lined autoclave and maintained at $180{ }^{\circ} \mathrm{C}$ for $24 \mathrm{~h}$. After the autoclave was cooled to room temperature, $\mathrm{Zn}_{0.3} \mathrm{Cd}_{0.7} \mathrm{~S}$ nanorods were washed with distilled water and absolute ethanol several times, and then vacuum dried at $60{ }^{\circ} \mathrm{C}$ overnight.

Synthesis of $10 \% \mathrm{ReS}_{2} / \mathbf{Z n}_{0.3} \mathrm{Cd}_{\mathbf{0 . 7}} \mathrm{S}$. $10.02 \mathrm{mg}$ of $\mathrm{NH}_{4} \mathrm{ReO}_{4}$, $5.62 \mathrm{mg}$ of thioacetamide $\left(\mathrm{C}_{2} \mathrm{H}_{5} \mathrm{NS}\right)$ and $400 \mathrm{mg}$ of CdS were dissolved in $40 \mathrm{ml}$ of $\mathrm{H}_{2} \mathrm{O}$. The reaction suspension was stirred vigorously for $30 \mathrm{~min}$ until a homogeneous dispersion was formed. The reaction mixture was added to a Teflon-lined stainless steel autoclave and maintained at $220{ }^{\circ} \mathrm{C}$ for $48 \mathrm{~h}$. After the autoclave was cooled to room temperature, $10 \% \mathrm{ReS}_{2} /$ $\mathrm{Zn}_{0.3} \mathrm{Cd}_{0.7} \mathrm{~S}$ was washed with distilled water and absolute ethanol for four times, and then vacuum dried at $60{ }^{\circ} \mathrm{C}$ overnight.

\subsection{Characterization}

The phase and crystal structures of the as-prepared samples were characterized by X-ray diffraction (XRD) on a Bruker D8 diffractometer using $\mathrm{Cu} K \alpha(\lambda=1.5406)$ radiation in the $2 \theta$ range from $5^{\circ}$ to $70^{\circ}$. X-ray photoelectron spectroscopy (XPS) data were obtained using a Thermo ESCALAB 250XI X-ray photoelectron spectrometer ( $\mathrm{Al} \mathrm{K} \alpha, 150 \mathrm{~W}, \mathrm{C} 1 \mathrm{~s} 284.8 \mathrm{eV}$ ). The high-resolution transmission electron microscopy (HRTEM) images and element mapping were obtained using JEOL JEM$2100 \mathrm{~F}$ (UHR) field emission transmission electron microscopy. UV-vis diffuse reflectance spectra (DRS) of the samples were determined using a UV-vis spectrometer (PerkinElmer, Lambda 850; $\mathrm{BaSO}_{4}$ as a reference) and recorded in the range of 200-800 nm. Time-resolved photoluminescence (PL) spectra (380 nm excitation) were recorded using an FLS980 multifunctional steady-state and transient fluorescence spectrometer (Edinburgh Instruments, room temperature). The transient surface photovoltage data were recorded using a $500 \mathrm{MHz}$ digital oscilloscope (TDS 3054C, Tektronix, Beaverton, OR, USA). An inductively coupled plasma (ICP) spectrometer (ICPE-9820, Shimadzu) was used to confirm the ionic concentration.

\subsection{Photocatalytic $\mathrm{H}_{2}$ production}

The photocatalytic hydrogen tests were conducted in a Labsolar-III AG closed gas circulation and exhaust system (Beijing Perfect Light Technology Co., Ltd, China) maintaining the photo-reaction temperature at $5{ }^{\circ} \mathrm{C}$ using a low-temperature thermostat bath (Poly Science, USA). In the photo-reaction system, $20 \mathrm{mg}$ of $\mathrm{ReS}_{2} / \mathrm{CdS}$ was suspended in $50 \mathrm{~mL}$ of DI water containing $2.1 \mathrm{~g}$ of $\mathrm{Na}_{2} \mathrm{~S}$ and $0.8 \mathrm{~g}$ of $\mathrm{Na}_{2} \mathrm{SO}_{3}$. A $300 \mathrm{~W}$ xenon lamp (PLS-SXE-300UV, Beijing Trusttech Co. Ltd, China) with a UV-cutoff filter (providing visible light $\lambda \geq 420 \mathrm{~nm}$ ) served as the visible-light source to trigger the water splitting reactions. To identify and quantify the gases produced, a volume of $1.5 \mathrm{~mL}$ of gas was sampled hourly and measured using a gas chromatograph (GC9790II, Zhejiang Fuli Analytical Instrument Co., Ltd, China) equipped with a thermal conductivity detector (TCD) and a $5 \AA$ molecular sieve column, where argon (Ar) was used as the carrier gas. The quantification of the $\mathrm{H}_{2}$ yield was based on a calibration curve.

\subsection{Apparent quantum efficiency (AQE) calculations}

The apparent quantum efficiency (AQE) was measured under the same photocatalytic reaction conditions, except for the wavelength of the incident light. For the $\mathrm{H}_{2}$ yields of $1 \mathrm{~h}$ photoreaction under monochromatic light, AQE was calculated by the following equation:

$$
\begin{aligned}
& \text { AQE }=\frac{N_{\mathrm{H}_{2}}}{N_{\mathrm{p}}}=\frac{\text { number of reacted electrons }}{\text { number of incident photons }} \times 100 \% \\
& =\frac{2 \times \text { the number of evolved } \mathrm{H}_{2} \text { molecules }}{\text { number of incident photons }} \times 100 \%
\end{aligned}
$$

\subsection{Photoelectrochemical measurements}

Photocurrent response, linear sweep voltammetry and electrochemical impedance of the catalysts were measured using an electrochemical workstation (CHI 630e) in a three-electrode quartz reactor using $0.5 \mathrm{M} \mathrm{Na}_{2} \mathrm{SO}_{4}$ solution and a mixed solution of $0.1 \mathrm{M} \mathrm{K}_{3}\left[\mathrm{Fe}(\mathrm{CN})_{6}\right]$ and $\mathrm{K}_{4}\left[\mathrm{Fe}(\mathrm{CN})_{6}\right] \cdot 3 \mathrm{H}_{2} \mathrm{O}$, respectively, as the 
electrolyte solutions. Linear sweep voltammetry (LSV) was carried out at a scan rate of $10 \mathrm{mV} \mathrm{s}^{-1}$ from 0.4 to $-0.6 \mathrm{~V}$. Working electrodes for samples were prepared by applying the doctorblading method. Then, $0.01 \mathrm{~g}$ of ethyl cellulose was dissolved in $15 \mathrm{ml}$ of ethanol with $0.1 \mathrm{~g}$ of catalyst. Subsequently, a glass stick was applied to FTO at a high-temperature using a layer of adhesive tape on the edge. Finally, it was dried in air and activated at $120{ }^{\circ} \mathrm{C}$ for $2 \mathrm{~h}$. All tests were conducted under visible light irradiation.

\subsection{In situ Fourier transform infrared spectrometer (FT-IR) analysis}

A Fourier transform infrared spectrometer (Nicolet IS-50) was used for in situ FT-IR measurements. The sample was filled into the in situ IR cell, and $\mathrm{Ar}$ and $\mathrm{H}_{2} \mathrm{O}$ gases were introduced into the cell and a fibre source (FX300, Beijing Perfect light Technology Co., Ltd, China) through the $\mathrm{CaF}_{2}$ window of the cell. Before the measurement, the sample was degassed at $423 \mathrm{~K}$ for $4 \mathrm{~h}$. The baseline was obtained after adsorption equilibrium on the sample for 1 h. $1 \% \operatorname{ReS}_{2} / \mathrm{Zn}_{0.3} \mathrm{Cd}_{0.7} \mathrm{~S}$ was used after treatment by $\mathrm{Na}_{2} \mathrm{~S}-\mathrm{Na}_{2} \mathrm{SO}_{3}$.

\subsection{On-line mass spectrometry analysis}

$10 \mathrm{ml}$ of $\mathrm{H}_{2} \mathrm{O} / \mathrm{D}_{2} \mathrm{O}$ with $10 \mathrm{mg}$ of photocatalyst and 2.1-0.8 $\mathrm{g}$ of $\mathrm{Na}_{2} \mathrm{~S}-\mathrm{Na}_{2} \mathrm{SO}_{3}$ was added to the closed quartz reactor (Beijing Perfect light Technology Co., Ltd, China). One end of the reactor was continuously fed with $\mathrm{Ar}$ and the other end was connected with the sampling port of the mass spectrometer (HPR-20 R\&D, Beijing Hiden Analytical Technology Co., Ltd, China). $\mathrm{H}_{2}$ and $\mathrm{D}_{2}$ were detected simultaneously in the MID mode of the SEM detector. After the MS baseline was stable, $300 \mathrm{~W}$ high pressure xenon lamp (PLS-SXE300, Beijing Perfect light Technology Co., Ltd, China) was used to illuminate the gas products in the reactor on-line.

\section{Results and discussions}

Structures and compositions of $\mathrm{ReS}_{2} / \mathrm{Zn}_{0.3} \mathrm{Cd}_{0.7} \mathrm{~S}$ (4 wt\% of $\operatorname{ReS}_{2}$ ) are visualized in Fig. 1. Fig. 1a and b show the XRD patterns of $\mathrm{CdS}, \mathrm{ZnS}, \mathrm{Zn}_{0.3} \mathrm{Cd}_{0.7} \mathrm{~S}$, $\mathrm{ReS}_{2} / \mathrm{Zn}_{0.3} \mathrm{Cd}_{0.7} \mathrm{~S}$, and the standard diffraction patterns of ZnS (PDF \#77-2100) and CdS (PDF \#77-2306). ${ }^{32}$ Compared with the standard diffraction peaks of $\mathrm{ZnS}$ and $\mathrm{CdS}$, the diffraction peaks of $\mathrm{Zn}_{0.3} \mathrm{Cd}_{0.7} \mathrm{~S}$ were shifted towards the lower-angle and higher-angle side, respectively, indicating that the sample is not a compound of $\mathrm{ZnS}$ and CdS, but a $\mathrm{Zn}_{0.3} \mathrm{Cd}_{0.7} \mathrm{~S}$ solid solution. After the loading of $\mathrm{ReS}_{2}$ on the surface of $\mathrm{Zn}_{0.3} \mathrm{Cd}_{0.7} \mathrm{~S}$, the diffraction peaks of $\mathrm{Zn}_{0.3} \mathrm{Cd}_{0.7} \mathrm{~S}$ were not shifted and no new peaks appeared. This indicates that the loading of $\mathrm{ReS}_{2}$ cannot affect the crystal structure of $\mathrm{Zn}_{0.3} \mathrm{Cd}_{0.7} \mathrm{~S}$. In addition, the value of full width at half maximum of the solid-soluble is found to be very large, which can be attributed to the different thickness of the $\mathrm{Zn}_{0.3} \mathrm{Cd}_{0.7} \mathrm{~S}$ and $\mathrm{ReS}_{2} / \mathrm{Zn}_{0.3} \mathrm{Cd}_{0.7} \mathrm{~S}$ samples. The loading of
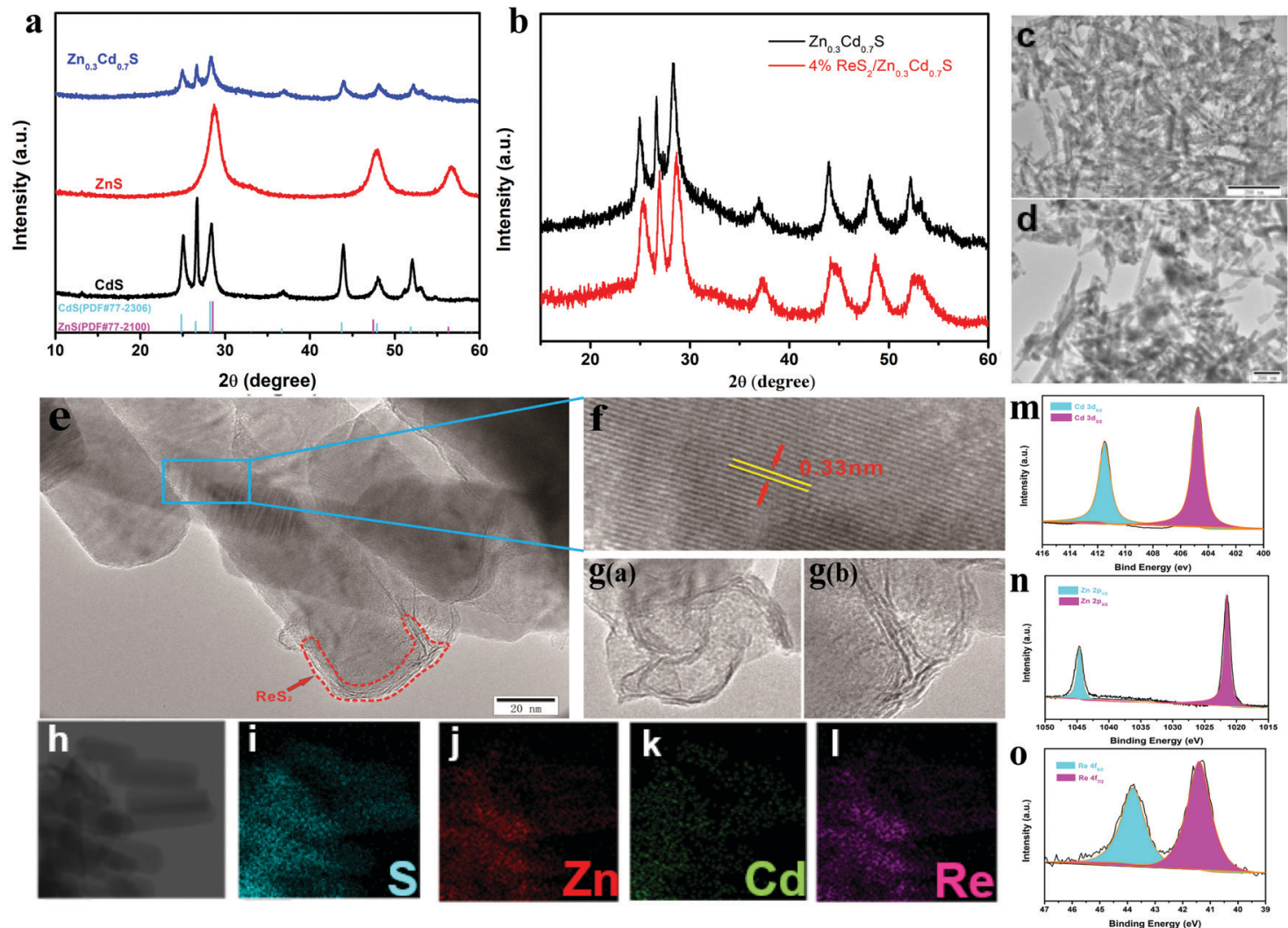

Fig. 1 Composition and morphological characterizations of $\mathrm{ReS}_{2} / \mathrm{Zn}_{0.3} \mathrm{Cd}_{0.7} \mathrm{~S}$. (a and b) XRD pattern, (c) $\mathrm{Zn}_{0.3} \mathrm{Cd}_{0.7} \mathrm{~S} T E M$ image, (d) ReS $/ \mathrm{Zn}_{0.3} \mathrm{Cd}_{0.7} \mathrm{~S}$ TEM image, (e-g) HRTEM image, (f) $\mathrm{Zn}_{0.3} \mathrm{Cd}_{0.7} \mathrm{~S}$ HRTEM image, (g) $\mathrm{ReS}_{2} / \mathrm{Zn}_{0.3} \mathrm{Cd} \mathrm{d}_{0.7} \mathrm{~S}$ HRTEM image, (h-l) EDS elemental mapping, and ( $\mathrm{m}-\mathrm{O}$ ) XPS analysis of $\mathrm{ReS}_{2} / \mathrm{Zn}_{0.3} \mathrm{Cd}_{0.7} \mathrm{~S}$. 
$\mathrm{ReS}_{2}$ onto $\mathrm{Zn}_{0.3} \mathrm{Cd}_{0.7} \mathrm{~S}$ did not significantly alter the nanorod morphology of $\mathrm{Zn}_{0.3} \mathrm{Cd}_{0.7} \mathrm{~S}$, but there were obvious interfaces formed between $\mathrm{ReS}_{2}$ and $\mathrm{Zn}_{0.3} \mathrm{Cd}_{0.7} \mathrm{~S}$, indicating that $\mathrm{ReS}_{2}$ is tightly bound to the $\mathrm{Zn}_{0.3} \mathrm{Cd}_{0.7} \mathrm{~S}$ nanorod surface. This finding is further confirmed by transmission electron microscopy (TEM) and high-resolution TEM (HRTEM) of $\mathrm{ReS}_{2} / \mathrm{Zn}_{0.3} \mathrm{Cd}_{0.7} \mathrm{~S}$ (Fig. 1c-g). HRTEM shows that the grid spacing of $\mathrm{ReS}_{2} /$ $\mathrm{Zn}_{0.3} \mathrm{Cd}_{0.7} \mathrm{~S}$ is $0.33 \mathrm{~nm}$, which is consistent with the XRD test results (Fig. 1f). In addition, element mapping of $\mathrm{ReS}_{2} /$ $\mathrm{Zn}_{0.3} \mathrm{Cd}_{0.7} \mathrm{~S}$ corresponding to the area is marked in Fig. 1, confirming that elemental $\mathrm{S}$ is uniformly dispersed in the whole selected area, while $\mathrm{Re}, \mathrm{Cd}$ and $\mathrm{Zn}$ are distributed separately, indicating that there is intimate contact between $\mathrm{ReS}_{2}$ and $\mathrm{Zn}_{0.3} \mathrm{Cd}_{0.7} \mathrm{~S}$. An effective interfacial contact can shorten the charge transfer distance and facilitate electron transfer between CdS and $\mathrm{Zn}_{0.3} \mathrm{Cd}_{0.7} \mathrm{~S}$. To further characterize the surface chemical composition and valence state, $\mathrm{ReS}_{2} / \mathrm{Zn}_{0.3} \mathrm{Cd}_{0.7} \mathrm{~S}$ was analyzed by X-ray photoelectron spectroscopy (XPS). As shown in Fig. 1m and n, the Cd 1s and Zn 2p XPS spectra demonstrate the structural characteristics of $\mathrm{Zn}_{0.3} \mathrm{Cd}_{0.7} \mathrm{~S}$. Fig. 10 shows two distinct peaks at 41.4 and $43.8 \mathrm{eV}$, which can be assigned to the $\operatorname{Re}_{7 / 2}$ and $\operatorname{Re} 4 f_{5 / 2}$ states of $\operatorname{Re}^{4+}$ in $\operatorname{ReS}_{2},{ }^{33}$ respectively. All the above results corroborate the successful deposition of $\mathrm{ReS}_{2}$ on the $\mathrm{Zn}_{0.3} \mathrm{Cd}_{0.7} \mathrm{~S}$ surface.

The effect of $\mathrm{ReS}_{2}$ modification on the optical properties of $\mathrm{Zn}_{0.3} \mathrm{Cd}_{0.7} \mathrm{~S}$ was studied by UV-vis diffusion reflection spectroscopy (Fig. 2a). After $\operatorname{ReS}_{2}$ was loaded, the light absorption of CdS and $\mathrm{Zn}_{0.3} \mathrm{Cd}_{0.7} \mathrm{~S}$ in the visible light absorption area was significantly enhanced, while the light absorption of pure CdS and $\mathrm{Zn}_{0.3} \mathrm{Cd}_{0.7} \mathrm{~S}$ was not very different, which indicates that the enhancement of visible light is due to the presence of $\mathrm{ReS}_{2}$. This may be attributed to the inherent high visible light capture capability of black $\mathrm{ReS}_{2}$ nanoparticles. According to the plot of $(\alpha h v)^{2}$ versus energy $(h v)$, the band gap value of $\mathrm{ReS}_{2} / \mathrm{Zn}_{0.3} \mathrm{Cd}_{0.7} \mathrm{~S}$ was significantly reduced, which is more conductive to the excitation of visible light. Mott-Schottky plots (Fig. S5, ESI $\dagger$ )
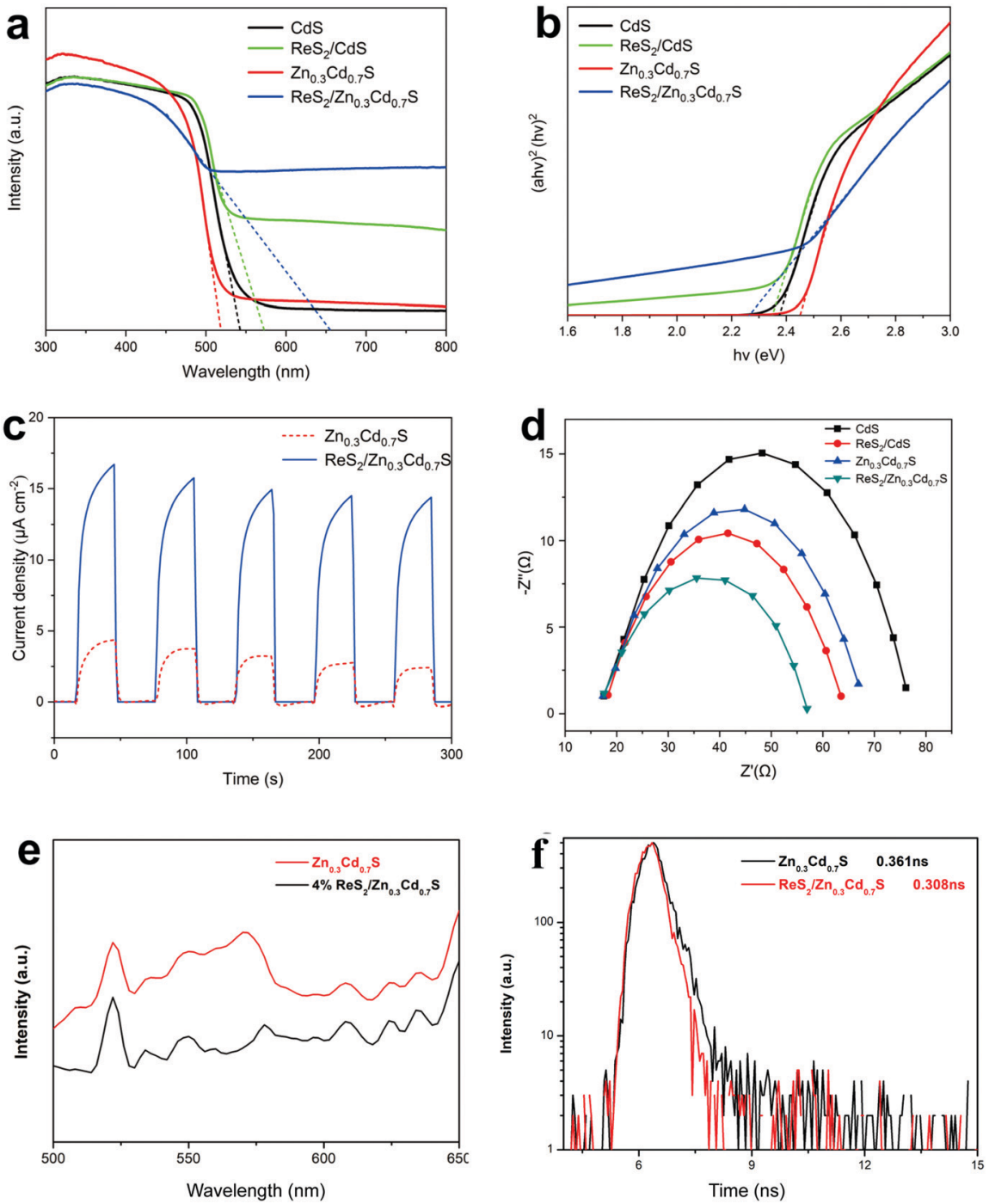

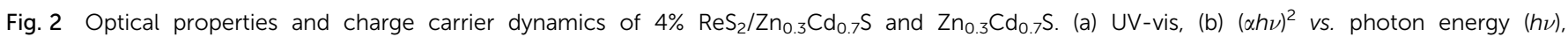
(c) photocurrent responses, (d) electrochemical impedance plots, (e) PL spectra, and (f) time-resolved PL spectra. 
and XPS price band spectrum (Fig. S6, ESI $\dagger$ ) also show that the price band of $\mathrm{ReS}_{2} / \mathrm{Zn}_{0.3} \mathrm{Cd}_{0.7} \mathrm{~S}$ is more negative, which can facilitate a reduction reaction.

To confirm and better understand the enhanced migration and separation of photo-induced charge carriers of $\mathrm{ReS}_{2}$ / $\mathrm{Zn}_{0.3} \mathrm{Cd}_{0.7} \mathrm{~S}$, photoelectrochemical measurements were performed. As expected, $\mathrm{ReS}_{2} / \mathrm{Zn}_{0.3} \mathrm{Cd}_{0.7} \mathrm{~S}$ showed a nearly 3 times higher photocurrent intensity than bare $\mathrm{Zn}_{0.3} \mathrm{Cd}_{0.7} \mathrm{~S}$, which indicates that $\mathrm{ReS}_{2}$ is an effective co-catalyst to promote the migration of photo-induced carriers (Fig. 2c). Meanwhile, the effect of $\mathrm{ReS}_{2}$ deposition on the kinetics of charge migration was further studied by electrochemical impedance spectroscopy (EIS). In comparison with pure $\mathrm{CdS}, \mathrm{ReS}_{2} / \mathrm{CdS}$, and $\mathrm{Zn}_{0.3} \mathrm{Cd}_{0.7} \mathrm{~S}$, the semicircle in the Nyquist plot of $\mathrm{ReS}_{2} /$ $\mathrm{Zn}_{0.3} \mathrm{Cd}_{0.7} \mathrm{~S}$ has a smaller radius, and it is indicative of accelerated charge transport and improved charge separation during photocatalysis, which demonstrates the prominent role of $\mathrm{ReS}_{2}$ nanoparticles as co-catalysts (Fig. 2d). Photoluminescence (PL) spectra (Fig. 2e) and time-resolved PL spectra (Fig. 2f) show that after the loading of $\mathrm{ReS}_{2}$ on $\mathrm{Zn}_{0.3} \mathrm{Cd}_{0.7} \mathrm{~S}$, more photocarriers are produced, and the lifetimes are $0.361 \mathrm{~ns}\left(\mathrm{Zn}_{0.3} \mathrm{Cd}_{0.7} \mathrm{~S}\right)$ and $0.308 \mathrm{~ns}\left(\mathrm{ReS}_{2} / \mathrm{Zn}_{0.3} \mathrm{Cd}_{0.7} \mathrm{~S}\right)$, indicating that the photogenerated carriers of $\mathrm{ReS}_{2} / \mathrm{Zn}_{0.3} \mathrm{Cd}_{0.7} \mathrm{~S}$ are more rapidly separated, and thus, hydrogen can be produced through a redox reaction.

Due to the unique characteristics of $\mathrm{ReS}_{2}$ in promoting light absorption and charge separation, we studied the role of $\mathrm{ReS}_{2}$ as a catalyst loaded on $\mathrm{Zn}_{x} \mathrm{Cd}_{1-x} \mathrm{~S}$ for photocatalytic hydrogen production. Fig. 3a shows the production of hydrogen for photocatalysts of solid-solubles with different $\mathrm{Zn}-\mathrm{Cd}$ ratios under the condition of visible light irradiation and $\mathrm{Na}_{2} \mathrm{~S}-\mathrm{Na}_{2} \mathrm{SO}_{3}$ as the sacrificial reagent. With the ratio of $\mathrm{Zn}$ and $\mathrm{Cd}$ in $\mathrm{Zn}_{x} \mathrm{Cd}_{1-x} \mathrm{~S}$ being changed, the test results for comparing photocatalytic hydrogen production are shown in Fig. 3a, and the optimal ratio product of $\mathrm{Zn}$ and $\mathrm{Cd}$ is $\mathrm{Zn}_{0.3} \mathrm{Cd}_{0.7} \mathrm{~S}\left(0.91 \mathrm{mmol} \mathrm{g}^{-1} \mathrm{~h}^{-1}\right)$. By adjusting the amount of loading of $\mathrm{ReS}_{2}$ (Fig. 3b), it can be found that the loading of $4 \mathrm{wt} \% \mathrm{ReS}_{2}$ on $\mathrm{Zn}_{0.3} \mathrm{Cd}_{0.7} \mathrm{~S}$ has the highest hydrogen production (92.45 $\mathrm{mmol} \mathrm{g}^{-1} \mathrm{~h}^{-1}$ ), which is 101 times higher than that of pure $\mathrm{Zn}_{0.3} \mathrm{Cd}_{0.7} \mathrm{~S}$. This shows that $\mathrm{ReS}_{2}$ can greatly improve the photocatalytic hydrogen production of $\mathrm{Zn}_{0.3} \mathrm{Cd}_{0.7} \mathrm{~S}$. To understand the details of enhanced photocatalytic hydrogen evolution, the apparent quantum efficiency (AQY) of $\mathrm{ReS}_{2}(4 \mathrm{wt} \%) / \mathrm{Zn}_{0.3} \mathrm{Cd}_{0.7} \mathrm{~S}$ was calculated at different irradiated wavelengths, as shown in Fig. $3 \mathrm{~b}$. At wavelengths of 400,420 , and $500 \mathrm{~nm}$, the AQY of $\mathrm{ReS}_{2}(4 \mathrm{wt} \%) / \mathrm{Zn}_{0.3} \mathrm{Cd}_{0.7} \mathrm{~S}$ is $23.24 \%, 20.95 \%$ and $0.88 \%$, respectively. The above results show that $\mathrm{ReS}_{2}$ is a very promising candidate as a common catalyst for hydrogen evolution. To determine the photocorrosion properties of CdS, we performed 30 hours of circulatory tests of $\mathrm{Zn}_{0.3} \mathrm{Cd}_{0.7} \mathrm{~S}$ and $\mathrm{ReS}_{2} / \mathrm{Zn}_{0.3} \mathrm{Cd}_{0.7} \mathrm{~S}$, as shown in Fig. $3 \mathrm{c}$ and d. A time period of five hours is considered as a group. The results show that $\mathrm{ReS}_{2} / \mathrm{Zn}_{0.3} \mathrm{Cd}_{0.7} \mathrm{~S}$ maintains a high photocatalytic hydrogen production performance even after 30 hours of light irradiation, with no significant reduction in yield. The above results confirm that $\mathrm{ReS}_{2} / \mathrm{Zn}_{0.3} \mathrm{Cd}_{0.7} \mathrm{~S}$ is a promising photocatalytic material with high photocatalytic activity and high cycling stability.

In the field of photocatalytic hydrogen production, sacrificial reagents are often used to improve the hydrogen production activity, but there may be hydrogen sources in these reagents. To confirm that water is indeed decomposed to hydrogen, isotope experiments were performed. When $\mathrm{Na}_{2} \mathrm{~S}-\mathrm{Na}_{2} \mathrm{SO}_{3}$ was
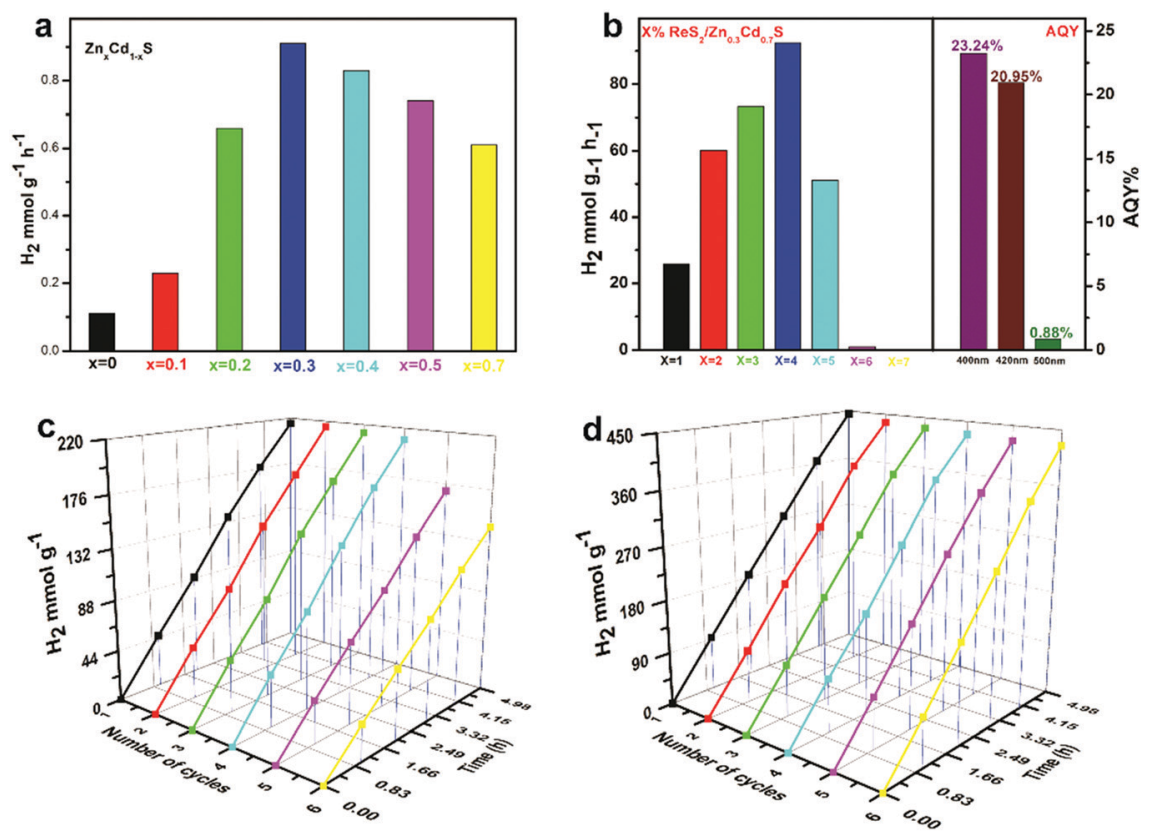

Fig. 3 Photocatalytic $\mathrm{H}_{2}$ evolution on $\mathrm{ReS}_{2} / \mathrm{Zn}_{0.3} \mathrm{Cd}_{0.7} \mathrm{~S}$ and $\mathrm{Zn}_{0.3} \mathrm{Cd}_{0.7} \mathrm{~S}$ photocatalysts. (a) Hydrogen generation rate of $\mathrm{Zn}_{x} \mathrm{Cd}_{1-x} \mathrm{~S}$ under visible-light irradiation, (b) hydrogen generation rate of $\mathrm{Zn}_{0.3} \mathrm{Cd}_{0.7} \mathrm{~S}$ with loading of $\mathrm{ReS}_{2}$ of different amounts under visible-light irradiation and apparent quantum efficiency under irradiation with monochromatic light at different wavelengths, (c) cycling tests of photocatalytic $\mathrm{H}_{2}$ evolution on $\mathrm{Zn}_{0.3} \mathrm{Cd}_{0.7} \mathrm{~S}$ under visible-light irradiation, and (d) cycling tests of photocatalytic $\mathrm{H}_{2}$ evolution on $\mathrm{ReS}_{2} / \mathrm{Zn}_{0.3} \mathrm{Cd}_{0.7} \mathrm{~S}$ under visible-light irradiation. 

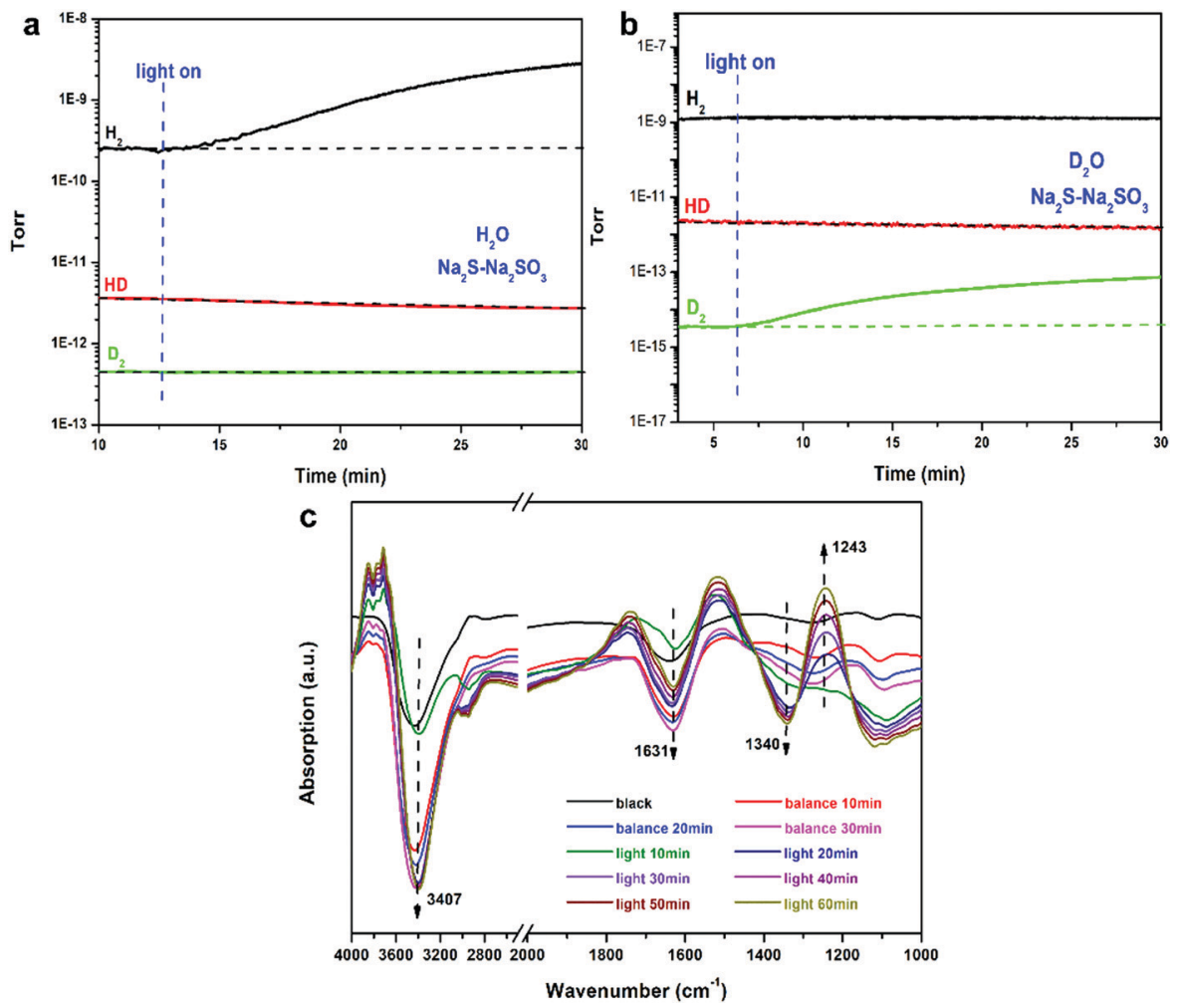

Fig. 4 In situ FT-IR spectra and on-line mass spectrometry of photocatalytic hydrogen production on $\mathrm{ReS}_{2} / \mathrm{Zn}_{0.3} \mathrm{Cd}_{0.7} \mathrm{~S}$ : (a) $\mathrm{H}_{2} \mathrm{O}$ solution of $\mathrm{Na}_{2} \mathrm{~S}-\mathrm{Na}_{2} \mathrm{SO}_{3}$; (b) $\mathrm{D}_{2} \mathrm{O}$ solution of $\mathrm{Na}_{2} \mathrm{~S}-\mathrm{Na}_{2} \mathrm{SO}_{3}$; (c) in situ FT-IR spectra of the $\mathrm{H}_{2} \mathrm{O}$ reaction on $\mathrm{ReS}_{2} / \mathrm{Na}_{2} \mathrm{~S}-\mathrm{Na}_{2} \mathrm{SO}_{3} \mathrm{with}^{\mathrm{N}} \mathrm{Na}_{2} \mathrm{~S}-\mathrm{Na}_{2} \mathrm{SO}_{3}$ as the sacrificial reagent.

used as the sacrificial reagent in $\mathrm{H}_{2} \mathrm{O}$ solution, only $\mathrm{H}_{2}$ was found and neither $\mathrm{HD}$ nor $\mathrm{D}_{2}$ was detected (Fig. 4a). In $\mathrm{D}_{2} \mathrm{O}$ solution, only $\mathrm{D}_{2}$ and no $\mathrm{H}_{2}$ or $\mathrm{HD}$ was detected (Fig. $4 \mathrm{~b}$ ). In addition, $\mathrm{H}_{2}$ and $\mathrm{D}_{2}$ were produced after light irradiation, and no signals of $\mathrm{H}_{2}$ and $\mathrm{D}_{2}$ were found under dark conditions, indicating that the hydrogen-producing reaction is performed under light-excited conditions and that the materials cannot produce hydrogen by themselves.

Fig. 4c shows the in situ FT-IR spectra of the $\mathrm{H}_{2} \mathrm{O}$ reaction on $\mathrm{ReS}_{2} / \mathrm{Zn}_{0.3} \mathrm{Cd}_{0.7} \mathrm{~S}$ when $\mathrm{Na}_{2} \mathrm{~S}-\mathrm{Na}_{2} \mathrm{SO}_{3}$ was used as the sacrificial reagent. The spectrum shows a peak at $3407 \mathrm{~cm}^{-1}$ which can be attributed to the stretching vibration of adsorbed $\mathrm{H}_{2} \mathrm{O}$ molecules. The two peaks at 1631 and $1340 \mathrm{~cm}^{-1}$ can be assigned to the stretching vibration of adsorbed $\mathrm{SO}_{3}{ }^{2-},{ }^{34-37}$ and the peak at $1243 \mathrm{~cm}^{-1}$ can be assigned to the stretching vibration of $\mathrm{SO}_{4}{ }^{2-}$. After illumination for $60 \mathrm{~min}$, the IR peaks of $\mathrm{H}_{2} \mathrm{O}$ and $\mathrm{SO}_{3}{ }^{2-}$ decreased with no obvious position change, while the IR peaks of $\mathrm{SO}_{4}{ }^{2-}$ increased with the increasing time of light illumination. This result indicates that $\mathrm{H}_{2} \mathrm{O}$ decomposition occurs during the photocatalytic hydrogen evolution, meanwhile, the $\mathrm{SO}_{3}{ }^{2-}$ as the sacrificial reagent can be oxidized to $\mathrm{SO}_{4}{ }^{2-}$. The above results are also confirmed by online mass spectrometry.

\section{Conclusions}

In summary, we successfully developed $\mathrm{ReS}_{2}$ as a highly efficient cocatalyst on $\mathrm{Zn}_{0.3} \mathrm{Cd}_{0.7} \mathrm{~S}$ nanorods for extraordinarily efficient photocatalytic hydrogen evolution. The optimal photocatalytic hydrogen evolution rate of $\mathrm{ReS}_{2} / \mathrm{Zn}_{0.3} \mathrm{Cd}_{0.7} \mathrm{~S}$ is $92.45 \mathrm{mmol} \mathrm{h}^{-1} \mathrm{~g}^{-1}$, and the best quantum efficiency is $23.24 \%$ at $400 \mathrm{~nm}$. What's more, there was no significant decrease in the photocatalytic activity after the 30 hours cycle of photocatalytic reaction. The excellent catalytic activity is due to the interaction between $\mathrm{Zn}_{0.3} \mathrm{Cd}_{0.7} \mathrm{~S}$ and $\mathrm{ReS}_{2}$ that inhibits the compound of photogenic runners. When the $\mathrm{Zn}$ elements are added to CdS, the photo-corrosive effect can be inhibited and they may synergize with the surface $\mathrm{ReS}_{2}$ to exhibit better photocatalytic properties. In addition, photocatalytic hydrogen evolution over $\mathrm{ReS}_{2} / \mathrm{Zn}_{0.3} \mathrm{Cd}_{0.7} \mathrm{~S}$ has been comprehensively elucidated at the molecular level using on-line mass spectrometry, and in situ FT-IR. It is anticipated that this work will promote the development of hydrogen production systems with advanced co-catalysts and provide extremely high photocatalytic activities.

\section{Conflicts of interest}

There are no conflicts to declare.

\section{Acknowledgements}

This work was supported by the National Natural Science Foundation of China (No. 51872147), the 111 Project (D20015), 
and the Program for Innovative Research Team of Science and Technology in the University of Henan Province (19IRTSTHN025).

\section{References}

$1 \mathrm{H}$. Kisch, Semiconductor Photocatalysis-Mechanistic and Synthetic Aspects, Angew. Chem., Int. Ed., 2013, 52, 812-847.

2 J. Li, X. Gao, B. Liu, Q. Feng, X. B. Li, M. Y. Huang, Z. Liu, J. Zhang, C. H. Tung and L. Z. Wu, Graphdiyne: A Metal-Free Material as Hole Transfer Layer To Fabricate Quantum Dot-Sensitized Photocathodes for Hydrogen Production, J. Am. Chem. Soc., 2016, 138, 3954-3957.

3 K. Honda and A. Fujishima, Electrochemical Photolysis of Water at a Semiconductor Electrode, Nature, 1972, 238, 37-38.

4 X. B. Chen, S. H. Shen, L. J. Guo and S. S. Mao, Semiconductor-based photocatalytic hydrogen generation, Chem. Rev., 2010, 110, 6503-6570.

5 X. Wang, K. Maeda, A. Thomas, K. Takanabe, G. Xin, J. M. Carlsson, K. Domen and M. Antonietti, A metal-free polymeric photocatalyst for hydrogen production from water under visible light, Nat. Mater., 2009, 8, 76-80.

6 L. Cheng, Q. Xiang, Y. Liao and H. Zhang, CdS-based photocatalysts, Energy Environ. Sci., 2018, 11, 1362-1391.

7 Y. J. Yuan, Z. T. Yu, D. Q. Chen and Z. G. Zou, Metal-complex chromophores for solar hydrogen generation, Chem. Soc. Rev., 2017, 46, 603-631.

8 L. Jing, W. Zhou, G. Tian and H. Fu, Surface tuning for oxide-based nanomaterials as efficient photocatalysts, Chem. Soc. Rev., 2013, 42, 9509-9549.

9 A. Nag, S. Sapra, C. Nagamani, A. Sharma, N. Pradhan, S. V. Bhat and D. D. Sarma, A Study of $\mathrm{Mn}^{2+}$ Doping in CdS Nanocrystals, Chem. Mater., 2007, 19, 3252-3259.

10 N. J. Borys, M. J. Walter, J. Huang, D. V. Talapin and J. M. Lupton, The role of particle morphology in interfacial energy transfer in CdSe/CdS heterostructure nanocrystals, Science, 2010, 330, 1371-1374.

11 J. Yang, H. Yan, X. Wang, F. Wen, Z. Wang, D. Fan, J. Shi and C. Li, Roles of cocatalysts in Pt-PdS/CdS with exceptionally high quantum efficiency for photocatalytic hydrogen production, J. Catal., 2012, 290, 151-157.

12 W. Zhang and R. Xu, Surface engineered active photocatalysts without noble metals: $\mathrm{CuS}-\mathrm{Zn}_{x} \mathrm{Cd}_{1-x} \mathrm{~S}$ nanospheres by one-step synthesis, Int. J. Hydrogen Energy, 2009, 34, 8495-8503.

13 C. Xing, Y. Zhang, W. Yan and L. Guo, Nano-CdS confined within titanate nanotubes for efficient photocatalytic hydrogen production under visible light illumination, Nanotechnology, 2019, 25, 035603.

14 C.-C. Chan, C.-C. Chang, C.-H. Hsu, Y.-C. Weng, K.-Y. Chen, H.-H. Lin, W.-C. Huang and S.-F. Cheng, Efficient and stable photocatalytic hydrogen production from water splitting over $\mathrm{Zn}_{x} \mathrm{Cd}_{1-x} \mathrm{~S}$ solid solutions under visible light irradiation, Int. J. Hydrogen Energy, 2014, 39, 1630-1639.

15 Y. Wang, J. Wu, J. Zheng, R. Jiang and $\mathrm{R}$. Xu, $\mathrm{Ni}^{2+}$-doped $\mathrm{Zn}_{x} \mathrm{Cd}_{1-x} \mathrm{~S}$ photocatalysts from single-source precursors for efficient solar hydrogen production under visible light irradiation, Catal. Sci. Technol., 2011, 1, 940-947.

16 J. D. Huang, J. Y. Liu and K. L. Han, Hybrid functionals studies of structural and electronic properties of $\mathrm{Zn}_{x} \mathrm{Cd}_{1}-{ }_{x} \mathrm{~S}$ and $\left(\mathrm{Zn}_{x} \mathrm{Cd}_{1-x}\right)\left(\mathrm{Se}_{x} \mathrm{~S}_{1-x}\right)$ solid solution photocatalysts, Int. J. Hydrogen Energy, 2012, 37, 17870-17881.

17 M. R. Gholipour, C. C. Nguyen, F. Béland and T. O. Do, Hollow microspheres consisting of uniform $\mathrm{Zn}_{x} \mathrm{Cd}_{1-x} \mathrm{~S}$ nanoparticles with noble-metal-free co-catalysts for hydrogen evolution with high quantum efficiency under visible light, J. Photochem. Photobiol., A, 2018, 358, 1-9.

18 X. Zong, H. Yan, G. Wu, G. Ma, F. Wen, L. Wang and C. Li, Enhancement of Photocatalytic $\mathrm{H}_{2}$ Evolution on CdS by Loading $\mathrm{MoS}_{2}$ as Cocatalyst under Visible Light Irradiation, J. Am. Chem. Soc., 2008, 130, 7176-7177.

19 K. Chang, X. Hai and J. Ye, Transition Metal Disulfides as Noble-Metal-Alternative Co-Catalysts for Solar Hydrogen Production, Adv. Energy Mater., 2016, 6, 1502555.

20 Q. Zhang, W. Wang, J. Zhang, X. Zhu, Q. Zhang, Z. Zhang Ren, S. Song, J. Wang, Z. Ying, R. Wang, X. Qiu, T. Peng and L. Fu, Highly Efficient Photocatalytic Hydrogen Evolution by $\mathrm{ReS}_{2}$ via a Two-Electron Catalytic Reaction, Adv. Mater., 2018, 30, 1707123.

21 Q. Zhang, W. Wang, J. Zhang, X. Zhu and L. Fu, Thermally Induced Bending of $\mathrm{ReS}_{2}$ Nanowalls, Adv. Mater., 2018, 30, 1704585.

22 H. Liu, B. Xu, J. M. Liu, J. Yin, F. Miao, C. G. Duan and X. G. Wan, Highly efficient and ultrastable visible-light photocatalytic water splitting over $\mathrm{ReS}_{2}$, Phys. Chem. Chem. Phys., 2016, 18, 14222-14227.

23 Q. Zhang, S. Tan, R. G. Mendes, Z. Sun, Y. Chen, X. Kong, Y. Xue, M. H. Rümmeli, X. Wu, S. Chen and L. Fu, Extremely Weak van der Waals Coupling in Vertical $\mathrm{ReS}_{2}$ Nanowalls for High-Current-Density Lithium-Ion Batteries, Adv. Mater., 2016, 28, 2616-2623.

24 M. Mao, C. Cui, M. Wu, M. Zhang, T. Gao, X. Fan, J. Chen, T. Wang, J. Ma and C. Wang, Flexible $\operatorname{ReS}_{2}$ nanosheets/ $\mathrm{N}$-doped carbon nanofibers-based paper as a universal anode for alkali (Li, Na, K) ion battery, Nano Energy, 2018, 45, 346-352.

25 H. Li, Z. Liang, Q. Deng, M. T. Hu, N. Du and W. Hou, Facile Construction of Defect-rich Rhenium Disulfide/Graphite Carbon Nitride Heterojunction via Electrostatic Assembly for Fast Charge Separation and Photoactivity Enhancement, ChemCatChem, 2019, 11, 1633-1642.

26 H. M. Liu, B. Xu, J. M. Liu, J. Yin, F. Miao, C. G. Duan and X. G. Wan, Highly efficient and ultrastable visible-light photocatalytic water splitting over $\mathrm{ReS}_{2}$, Phys. Chem. Chem. Phys., 2016, 18, 14222-14227.

27 J. A. Song, R. R. Sun, Y. L. Chen, D. J. Sun and X. Y. Li, L-Cysteine assisted synthesis of $\mathrm{Zn}_{0.5} \mathrm{Cd}_{0.5} \mathrm{~S}$ solid solution with different morphology, crystal structure and performance for $\mathrm{H}_{2}$ evolution, Int. J. Hydrogen Energy, 2018, 43, 18220-18231.

28 Y. T. Lu, D. D. Wang, P. Yang, Y. K. Dua and C. Lu, Coupling $\mathrm{Zn}_{x} \mathrm{Cd}_{1-x} \mathrm{~S}$ nanoparticles with graphene-like $\mathrm{MoS}_{2}$ : superior 
interfacial contact, low overpotential and enhanced photocatalytic activity under visible-light irradiation, Catal. Sci. Technol., 2014, 4, 2650-2657.

29 H. T. Zhao, R. R. Sun, X. Y. Li and X. Sun, Enhanced photocatalytic activity for hydrogen evolution from water by $\mathrm{Zn}_{0.5} \mathrm{Cd}_{0.5} \mathrm{~S} / \mathrm{WS}_{2}$ heterostructure, Mater. Sci. Semicond. Process., 2017, 59, 68-75.

30 J. A. Song, Y. L. Chen, D. J. Sun and X. Y. Li, Perylenetetracarboxylic diimide modified $\mathrm{Zn}_{0.7} \mathrm{Cd}_{0.3} \mathrm{~S}$ hybrid photocatalyst for efficient hydrogen production from water under visible light irradiation, Inorg. Chem. Commun., 2018, 92, 27-34.

31 Q. Li, H. Meng, J. G. Yu, W. Xiao, Y. Q. Zheng and J. Wang, Enhanced Photocatalytic Hydrogen-Production Performance of Graphene- $\mathrm{Zn}_{x} \mathrm{Cd}_{1-x} \mathrm{~S}$ Composites by Using an Organic $\mathrm{S}$ Source, Chem. - Eur. J., 2014, 20, 1176-1185.

32 J. Song, Q. Tian, J. Gao, H. Wu, Y. Chen and X. Li, Controlled preparation of CdS nanoparticle arrays in amphiphilic perylene tetracarboxylic diimides: organization, electrontransfer and semiconducting properties, CrystEngComm, 2014, 16, 1277-1286.
33 C. M. Corbet, C. McClellan, A. Rai, S. S. Sonde, E. Tutuc and S. K. Banerjee, Field Effect Transistors with Current Saturation and Voltage Gain in Ultrathin $\mathrm{ReS}_{2}$, ACS Nano, 2015, 9, 363-370.

34 F. Li, Q. Gu, Y. Niu, R. Wang, Y. Tong, S. Zhu, H. Zhang, Z. Zhang and X. Wang, Hydrogen evolution from aqueousphase photocatalytic reforming of ethylene glycol over $\mathrm{Pt} / \mathrm{TiO}_{2}$ catalysts: role of $\mathrm{Pt}$ and product distribution, Appl. Surf. Sci., 2017, 391, 251-258.

35 H. A. Al-Abadleh and V. H. Grassian, FT-IR study of water adsorption on aluminum oxide surfaces, Langmuir, 2003, 19, 341-347.

36 E. Yoda, FT-IR Study of Dissociative Water Adsorption on 1-Butyl-3-methylimidazolium Exchanged Mordenite Zeolite, J. Phys. Chem. C, 2009, 113, 9851-9856.

37 L. Li, R. Bennett, W. Conway, H. Yu, S. Clifford, M. Maeder and G. Puxty, Development and Evaluation of a Novel Method for Determining Absorbent Composition in Aqueous Ammonia-Based $\mathrm{CO}_{2}$ and $\mathrm{SO}_{3}{ }^{2-}$ and $\mathrm{SO}_{4}{ }^{2-}$ Loaded Capture Process Solutions via FT-IR Spectroscopy, Energy Fuels, 2018, 32, 8563-8570. 